\title{
EVALUATION OF RENAL FUNCTION IN DONAR FOLLOWING KIDNEY DONATION
}

\author{
MOHAMMED MIZANUR RAHMAN ${ }^{1}$, MD.WALIUL ISLAM ${ }^{1}$, PROBIR KUMAR ROY'1, KARTIK CHANDRA \\ GHOSH$^{2}$, MOHAMMAD AL AMIN ${ }^{1}$
}

${ }^{1}$ Department of Urology, National Institute of Kidney Diseases \& Urology, Dhaka, Bangladesh, ${ }^{2}$ Department of Urology, Dhaka Medical College, Dhaka, Bangladesh

\begin{abstract}
Objectives: To find out any changes in renal function in donor following kidney donation.

Materials and Methods: A Hospital based prospective study was conducted in the Department of Urology of Bangabandhu Sheikh Mujib Medical University, Dhaka, Bangladesh from April 2011 to September 2012, Investigations included specific gravity and urinary microalbumin, ultrasonogram of kidneys, serum creatinine, estimated glomerular filtration rate. According to inclusion and exclusion criteria a total of 37 donors were enrolled in this study. Subsequent follow up were taken at the end of three months, six months and nine months. Data were evaluated by Paired t-test, Significance was defined $p$ value $<0.05$.
\end{abstract}

Results: The age range varied from 25 to 39 years and almost a half (45.9\%) of patients had age belonged to 25-30 years and male to female ratio was 1:2.4. The mean baseline specific gravity was $1016.97 \pm 8.03$, serum creatinine $1.03 \pm 0.24$. The baseline urinary microalbumin was found nil and subsequent $1^{\text {st }}, 2^{\text {nd }}$, and $3^{\text {rd }}$ follow up were also nil. The mean difference of specific gravity, serum creatinine $(\mathrm{mg} / \mathrm{dl})$ and GFR estimated by cretainine clearance rate and DPTA were almost consistent between baseline and the subsequent follow-up, no statistical significant $(P>0.05)$ was found between baseline and the subsequent follow-up.

Conclusion: Renal function of the remaining kidney in living donors does not significantly change after donor nephrectomy.

Key words: Renal Function, Kidney Donation.

Bangladesh J. Urol. 2016; 19(1): 18-22

\section{Introduction}

Kidney transplantation is a standard treatment for patients with end-stage renal disease which confers a survival benefit and is cost effective compared with haemodialysis. Living kidney donation is the main source in many countries, because the outcomes of cadaver transplantations are poor[1].

The inadequate supply of deceased donor kidneys is one of the factors to increase the number of living donor kidney transplants. The advantages of living donor renal transplantation compared with deceased donor renal transplantation are better for graft survivals, less recipient morbidity, specific planning of the operation.

Correspondence: Mohammed Mizanur Rahman, Department of Urology, National Institute of Kidney Diseases \& Urology, Dhaka, Bangladesh, Email: mizan_1616@y ahoo.com
Renal function is thoroughly evaluated before live kidney donation. Potential kidney donors were also evaluated before donation. However, owing to increased demand for organs, some kidney transplant centers are becoming more willing to accept the living donors with regard to increase age, obesity, or low/normal glomerular filtration rate[2].

Living donor kidney transplantation provides superior allograft function for the recipients with a low risk of complications such as hypertension and chronic kidney disease for donors.

Studies after live donor nephrectomy suggest that the long-term risk to the donor of developing end-stage renal disease is similar to the general population. The longterm safety of nephrectomy depends on careful screening to identify healthy donors with excellent renal 
function and a low likelihood of developing progressive disease in the remaining kidney[4].

Live donor kidney transplantation has excellent result for patient and graft survival with advances in immunesuppression and medical management. Follow-up studies of the live donors indicate that kidney donation is currently a safe procedure with low morbidity and mortality[5].

The major reasons leading to improved outcomes are more potent due to selective immunosuppression, better surgical techniques, more sensitive cross-matching and better prophylaxis and treatment of morbid infections. There is also an emerging consensus that preemptive transplantation, immediately prior to the need to dialysis, is advantageous in reducing morbidity and mortality.

The present study is designed to find out any Changes of renal function following unilateral kidney donation.

\section{Materials and methods}

A Hospital based prospective study was conducted in the Department of Urology of Bangabandhu Sheikh Mujib Medical University, Dhaka, Bangladesh from April 2011 to September 2012, to find out Changes of renal function following unilateral kidney donation in whom renal function were within normal limit prior to donation. History, clinical examinations and investigations are necessary to identify the potential complications and outcomes. Investigations were included specific gravity from routine microscopic examination of urine and serum creatinine and Glomerular filtration rate estimated by cretainine clearance rate using Cock-croft-gault formula and DTPA renogram. According to inclusion and exclusion criteria a total of 37 donors were enrolled in this study. Then purposive sampling was applied to collect sample from all kidney donors or participants by inclusion and exclusion criteria. By seeing the dependent variable of donors from investigations reports which were done in the various government hospitals or recognised private clinics. In analyzer machine, serum creatinine was estimated by enzymatic method using picric acid containing reagent. Total 37 donors were collected by this technique in my study period.

Subsequent follow up were taken at the end of third month, sixth month and ninth month following nephrectomy by :

1) Specific gravity from routine microscopic examination of urine

2) Serum creatinine

4) Glomerular filtration rate estimated by cretainine clearance rate using Cock-croft-gault formula and DTPA renogram.

\section{Result}

A total of 37 Donors were included in this study. Majority number of Donors were found belonged to 25-30 years. The mean age was found $31.41 \pm 3.99$ years with range from 25 to 39 years.Male was found $29.7 \%(11)$ and female was $70.3 \%(26)$. Male female ratio was 1:2.4.(Table I).

Table I

Age and sex distribution of the donors ( $n=37)$.

\begin{tabular}{lcc}
\hline & Number of Donor & Percentage \\
\hline Age (in years) & 17 & $45.9 \%$ \\
$25-30$ & 12 & $32.4 \%$ \\
$31-35$ & 8 & $21.6 \%$ \\
$36-40$ & 31.41 & \pm 3.99 \\
Mean \pm SD & $(25$ & $-39)$ \\
Range (min-max) & & \\
Sex & 11 & $29.7 \%$ \\
Male & 26 & $70.3 \%$ \\
Female & &
\end{tabular}

Table II shows the specific gravity of the urine to assess the renal function. The mean before transplant specific gravity of urine was found in $1016.97 \pm 8.03,1^{\text {st }}$ follow up specific gravity was $1014.02 \pm 6.57,2^{\text {nd }}$ follow specific gravity was $1017.4 \pm 6.9$ and $3^{\text {rd }}$ follow up specific gravity was $1015.64 \pm 5.75$. The difference was not statistically significant $(P>0.05)$ between different follow up in paired $\mathrm{t}$-test. The mean of serum creatinine before transplant was found $1.03 \pm 0.24,1^{\text {st }}$ follow up serum creatinine was $0.96 \pm 0.22,2^{\text {nd }}$ follow up serum creatinine was $1.09 \pm 0.22$ and $3^{\text {rd }}$ follow up serum creatinine was $1.0 \pm 0.21$. The difference was not statistically significant $((P>0.05)$ between different follow up in paired t-test.

Table III shows the Glomerular filtration rate estimated by cretainine clearance rate using Cock-croft-gault formula and DTPA renogram. The mean before transplant glomerular filtration rate was found $98.35 \pm 4.92,1^{\text {st }}$ follow up glomerular filtration rate was $100.19 \pm 5.52,2^{\text {nd }}$ follow up glomerular filtration rate was $98.95 \pm 6.68$ and $3^{\text {rd }}$ follow up glomerular filtration rate was $100.46 \pm 5.24$. In case of Glomerular filtration rate by DPTA similar scenario was found. The mean Before transplant glomerular filtration rate was found $106.24 \pm 8.27,1^{\text {st }}$ follow up glomerular filtration rate was $105.58 \pm 8.42,2^{\text {nd }}$ follow up glomerular filtration rate was $105.45 \pm 9.43$ and $3^{\text {rd }}$ follow up glomerular filtration rate was $103.53 \pm 8.89$. The difference was not statistically significant $(P>0.05)$ between different follow up in paired t-test. 
Table II

Distribution of specific gravity $(n=37)$

\begin{tabular}{lccc}
\hline & Mean \pm SD & (Min-max) & P value \\
\hline Specific Gravity & & & \\
Before transplant & $1016.97 \pm 8.03$ & $(1003-1029)$ & \\
$1^{\text {st }}$ follow up at the end of3 months & $1014.02 \pm 6.57$ & $(1003.17-1025.15)$ & $0.088^{\text {ns }}$ \\
$2^{\text {nd }}$ follow up at the end of6 months & $1017.4 \pm 6.9$ & $(1006.36-1027.9)$ & $0.805^{\text {ns }}$ \\
$3^{\text {rd }}$ follow up at the end of 9 months & $1015.64 \pm 5.75$ & $(1006.02-1025.58)$ & $0.415^{\text {ns }}$ \\
Serum creatinine $(\mathrm{mg} / \mathrm{dl})$ & & & \\
Before transplant & $1.03 \pm 0.24$ & $(0.6-1.4)$ & $0.195 \mathrm{~ns}$ \\
$1^{\text {st }}$ follow up at the end of 3 months & $0.96 \pm 0.22$ & $(0.6-1.4)$ & $0.266 \mathrm{~ns}$ \\
$2^{\text {nd }}$ follow up at the end of6 months & $1.09 \pm 0.22$ & $(0.7-1.4)$ & $0.569 \mathrm{~ns}$ \\
$3^{\text {rd }}$ follow up at the end of9 months & $1.0 \pm 0.21$ & $(0.6-1.4)$ & \\
\hline
\end{tabular}

Table III

Glomerular filtration rate estimated by cretainine clearance rate and DTPA renogram using Cock-croft-gault formula

\begin{tabular}{lccc}
\hline Glomerular Filtration Rate & Mean \pm SD & (Min-max) & P value \\
\hline Before transplant & $98.35 \pm 4.92$ & $(91-108)$ & \\
$1^{\text {st }}$ follow up at the end of 3 months & $100.19 \pm 5.52$ & $(90-109)$ & $0.134^{\mathrm{ns}}$ \\
$2^{\text {nd }}$ follow up at the end of 6 months & $98.95 \pm 6.68$ & $(90-110)$ & $0.661^{\mathrm{ns}}$ \\
$3^{\text {rd }}$ follow up at the end of 9 months & $100.46 \pm 5.24$ & $(92-109)$ & $0.078^{\mathrm{ns}}$ \\
DTPA & & & \\
Pre-transplant & $106.24 \pm 8.27$ & $(91-119)$ & $0.724 \mathrm{~ns}$ \\
1st follow up at the end of 3 months & $105.58 \pm 8.42$ & $(92-117)$ & $0.690 \mathrm{~ns}$ \\
2nd follow up at the end of 6 months & $105.45 \pm 9.43$ & $(90-119)$ & $0.172 \mathrm{~ns}$ \\
\hline 3rd follow up at the end of 9 months & $103.53 \pm 8.89$ & $(91-119)$ &
\end{tabular}

* $\mathrm{SD}=$ Standard deviation, min=minimum, max=maximum, ns=not significant

*paired t-test was done

\section{Discussion}

In this current study it was observed that the mean age was $31.41 \pm 3.99$ years with range from 25 to 39 years. Similarly, Azar et al. showed the mean age at the time of donation was $28.97 \pm 4.75$ years with range from 18 to 47 years, which is comparable with the current study. In another studies a higher mean age observed by Chien et al. [6] Freedland et al. [7] and Reese et al. The higher age range may be due to increased life expectancy in their study donor. Younger donors exhibit a capacity for hyperfiltration that remains for several years, whereas renal function declines in the elderly. In this current series it was observed that male and female donors were found $29.7 \%$ and $70.3 \%$ respectively, where male to female ratio was $1: 2.4$, which indicates that female donor is predominant. Similar observations regarding the female predominant donor were also made by Gossmann et al.[8] Freedland et al. and Reese et al. while Azar et al. showed male predominant.

Hamza et al.[9] found that renal function parameters such as serum creatinine, showed a relevant increase between 12 and 18 hours after donor nephrectomy. The time to increase differed slightly between individual parameters. At day 4, there was no significant difference between the initial and final values, except urine microglobulin, which indicates an impaired tubular function. In this study it was observed that the mean baseline serum creatinine was $1.03 \pm 0.24 \mathrm{mg} / \mathrm{dl}$ varied from $0.6-1.4 \mathrm{mg} / \mathrm{dl}$, not much significant difference was 
found in consecutive follow ups. which are similar with Mjoen et al. and Nozaki et al.[10] In another study Chien et al. Lind et al [11] and Siebels et al.[12] showed mean serum creatinine increased after donation of the kidney. However, most reports compared donor renal function with both kidneys before nephrectomy with that of the single nondonated kidney after nephrectomy. Such analysis can not demonstrate the actual functional change in the preserved kidney after Laparoscopic donor nephrectomy.

GFR were almost consistent during baseline and the subsequent follow-up and no significant difference was found between different follow up. Similar outcome was found in case of GFR measured by DPTA in present study. Almost similar findings also obtained by Bohlouli et al. and Garg et al.[13] Cohney et al. observed the average decrement in glomerular filtration rate (22 studies) in donors with normal renal function after donation was $26 \mathrm{~mL} / \mathrm{min}$ per $1.73 \mathrm{~m}^{2}$ (range 8-50). After 10 years (8 studies) $40 \%$ (range $23-52 \%$ ) of donors had a glomerular filtration rate between 60 and $80 \mathrm{~mL} /$ min per $1.73 \mathrm{~m}^{2}, 12 \%$ (range $0-28 \%$ ) had a glomerular filtration rate between 30 and $59 \mathrm{~mL} / \mathrm{min}$ per $1.73 \mathrm{~m}^{2}$ and $0.2 \%$ (range $0-2.2 \%$ ) had a glomerular filtration rate less than $30 \mathrm{~mL} / \mathrm{min}$ per $1.73 \mathrm{~m}^{2}$. In the 6 controlled studies where average follow up was at least 5 years, the post-donation weighted mean difference in glomerular filtration rate among the donors compared with controls was $10 \mathrm{~mL} / \mathrm{min}$ per $1.73 \mathrm{~m}^{2}$.

Jeon et al.[15] studied the association between preoperative kidney volume, and volume change and delayed kidney function recovery in donors. Younger age $(p<0.001)$ and lower preoperative volume of the remaining kidney $(p=0.019)$ were significant predictors of a greater increase in kidney volume. Preoperative kidney volume is an independent predictor of the volume increase and delayed kidney function recovery in donors that could be used clinically.

\section{Conclusion}

This study was undertaken to observe any deterioration of donor renal function after donor nephrectomy. This study demonstrates that renal function of the remaining kidney in living donors do not significantly change after donor nephrectomy.

\section{References}

1. Azar, SA, Nakhjavani, MR, Tarzamni, MK, Faragi, A, Bahloli, A\& Badroghli, N 2007, 'Is Living Kidney Donation Really Safe', Transplantation Proceedings, vol. 39, pp.822-823.
2. Mjøen, G, Øyen, O, Midtvedt, K, Dahle, DO, Norby, G \& Holdaas, H 2011,'Age, gender, and body mass index are associated with renal function after kidney donation', Clinical Transplantation, vol. 25HYPERLINK "http://hinari-gw.who.int/ whalecomonlinelibrary.wiley.com/whalecom0/doi/ 10.1111/ctr.2011.25.issue-6/issuetoc", HYPERLINK "http://hinari-gw.who.int/whalecomonlinelibrary. wiley.com/whalecom0/doi/10.1111/ctr.2011.25. issue-6/issuetoc"HYPERLINK "http://hinarigw.who.int/whalecomonlinelibrary.wiley.com/ whalecom0/doi/10.1111/ctr.2011.25.issue-6/ issuetocpp. 579-583.

3. Henze, A, Raila, J, Kempf, C, Reinke, P, Sefrin, A , Querfeld U et al. 2011, 'Vitamin A metabolism is changed in donors after living-kidney transplantation: an observational study', Lipids Health Dis, vol. 7, pp.231-237.

4. Reese, PP, Simon, MK, Stewart, J \& Bloom, JJ 2009, 'Medical Follow-up of Living Kidney Donors by 1 Year After Nephrectomy', Transplantation Proceedings, vol. 41, pp. 3545-3550.

5. Bohlouli, A, Tarzamni, MK, Zomorodi, A, Abdollahifard, S, Hashemi, B \& Nezami, N 2010, 'Remnant kidney function and size in living unrelated kidney donors after nephrectomy', Saudi J Kidney Dis Transpl, vol. 21, pp.246-250.

6. Chien, $\mathrm{CH}$, Wang, $\mathrm{HH}$, Chiang, YJ, Chu, $\mathrm{SH}$, Liu, HE \& Liu, KL 2010, 'Change in Renal Function After Laparoscopic Donor Nephrectomy for Kidney Transplantation', Transplantation Proceedings, vol. 42, pp. 692-695.

7. Freedland, SJ, Blanco-Yarosh, M, Sun, JC, Hale, SJ, Elashoff, DA, Rajfer, JA, et al. 2002 , 'Effect of ketorolac on renal function after donor nephrectomy', Urology, vol. 59,pp. 826-830.

8. Gossmann, J, Wilhelm, A, Kachel, HG, Jordan, J, Sann, U , Geiger, H , et al. 2005, 'Long-term consequences of live kidney donation follow-up in $93 \%$ of living kidney donors in a single transplant center', Am J Transplant, vol. 5, pp.2417-24.

9. Hamza, A, Wagner, S \& Weigand, K 2008, 'Transperitoneal, hand assisted laparoscopic donor nephrectomy: surveillance of renal function by immune monitoring', Transpl Proc, vol. 40, pp.895901. 
10. Nozaki, T, Ishida, $\mathrm{H}$, Tokumoto, $\mathrm{T}$, Shirakawa, $\mathrm{H}$, Shimizu, T , Omoto, K, et al. 2010, 'Risk Factors for Deterioration of Renal Function After Donor Nephrectomy', Transplantation Proceedings, vol. 42, pp.1476-1478.

11. Lind, MY, Borg, IMZ, Hazebroek, EJ , Hop, WCJ , Alwayn , IPJ , Weimar, W, et al. 2005, 'The effect of laparoscopic and open donor nephrectomy on the long-term renal function in donor and recipient: a retrospective study', Transplantation, vol. 80, pp. 700-703.

12. Siebels, M, Theodorakis, J, Schmeller, N, Corvin, S, Burchardi, NM, Hillebrand, G, et al. 2003, 'Risks and complications in 160 living kidney donors who underwent nephroureterectomy', Nephrol Dial Transplant, vol. 18, pp.2648-2654.

13. Garg, AX, Muirhead, N \& Knoll, G 2006, 'Proteinuria and reduced kidney function in living kidney donors: A systematic review, meta-analysis, and metaregression', Kidney Int, vol. 70, pp.1801-1810.

14. Cohney, S, Kanellis, J \& Howell, M 2009, 'Donor renal function', Nephrology, vol. 15, pp.137-145

15. Jeon, HG, Lee, SR, Joo, DJ, Oh, YT, Kim, MS , Kim, YS , et al. 2010, 'Predictors of kidney volume change and delayed kidney function recovery after donor nephrectomy', J Urol, vol. 184, pp.1057-63.

\footnotetext{
Abbreviations:

DTPA : Diethylenetriamine Pentaacetic Acid

GFR : Glumerular Filtration Rate
} 